\title{
The Prevalence of Voice Disorders in Secondary School Teachers in South west Nigeria
}

\author{
Johnson K.J. ${ }^{1}$,Akinola M.A ${ }^{2}$,Okonkwo K.C ${ }^{3}$. \\ ENT Unit, Department Of Surgery Babcock University Teaching Hospital, Ilishan, Remo, Ogunstate, Nigeria.
}

\begin{abstract}
Background: Voice disorders are one of the major occupational hazards of school teachers.This study was carried out to determine the prevalence of voice disorders and identify possibleassociated risk factors amongsecondary school teachers.

Method: A 25-item questionnaire was administered to 143 secondary school teachers from six schools in Ilishan Remo area of western Nigeria.

Result: Out of 143 teachers, 89 (62.2\%- 45 males and44 females ) reported voiceproblems without any significant difference in both sexes.

The most frequent voice change was low voice (39\%).Most voice disorders weremanaged at home (39\%)Demographic, work related factors, healthand behavioral risk factors had little or no visible effect on the prevalence of voice disorders.

Conclusion: Voice disordersposessignificant threat to the health and profession of secondary school teachers. The demographic, work related variables and health /behavioral risk factors associated with voice disorders in prior studies were not significantin this study.
\end{abstract}

Keywords: Prevalence, voice disorders, risk factors

\section{Introduction}

Voice disorders are defined as problems of voice involving abnormal pitch, loudness, or quality of sound produced by the laryn ${ }^{1}$.Voice disorders are characterized by lack of audiblility or stablility, inappropriate for the gender and age of the speaker.Voice disorders are associated with easy fatigability, pain and discomfort on phonation. ${ }^{1}$ TheTeachers who are classified as vocal professionals, are therefore not capable of fulfilling the requiredlinguistic and paralinguistic functions.Voice disorders can be organic or non-organic. The latter is often referred to as functional or psychogenic. They are non-physical in origin or results from faulty habit of voice use. The voice sounds abnormal despite normal laryngeal anatomy. Voice disorders can also be categorised into habitual voice problems secondary to vocal misuse or abuse, and psychogenic vocal problems. Voice misuse or overuse is often associated with physical changes in the larynx, such as muscle tension and fatigues, and vocal pathologies such as nodules or polyps. A variety of symptoms associated with heavy voice use include: hoarseness, decreased loudness and discomfort.

Voice misuse or overuse is common among individuals who use their voice often, like the teachers, preachers, commercial bus conductors and singers. For heavy occupational voice users this problem can impede their work performance ${ }^{2}$. Voice disorders were thought to occur more often in the older age groups due to agerelated anatomical changes involving the vocal apparatus. Women have also been found to be at higher risk for voice disorders than men due to increased vibratory rate of vocal cord in women increasing their susceptibility to mild trauma over time.Also, a number of medical conditions such as cold,influenza,respiratory allergy, acid reflux,and social behaviors involving tobacco smoking and excessive alcohol intake have been associated with increased risk of voice disorders.

The prevalence of voice disorders has often been examined among individuals who rely on their voice for their profession e.g. singers, preachers, and teachers.Voice health problems are considered as one of the important occupational hazards affecting school teachers.Teachers need an effective functioning of the phonatory system for the exercise of their profession. The phonatory dysfunctions that develop or exacerbate in the course of their activity manifest as symptoms of voice disorders.Studies have shown that the prevalence of voice disorders, ranging from $11 \%$ to $50 \%$ in USA, Europe, and Nigeria ${ }^{3}$ is higher among teachers than other professionals.In the process of teaching, certain conditions such as:excessive hour load spent on direct activities with students, intensive use of loud voice as a resource in noisy classroom, deficient acoustics, ventilation and aeration in the classrooms and the exaggerated number of students in the classroom, ${ }^{4}$ exist that trigger disorders in the phonatory systemespecially in developing countries like Nigeria.Demographic variables like gender and age have been considered to be possible risk factors for the development of voice disorders ${ }^{5}$. The objective of this study was to determine the prevalence of voice disorders among secondary school teachers and to ascertain possible associated risk factors to inform policy and support services for school teachers. 


\section{Study design}

\section{Method}

This was a cohortof community based study conducted amongall secondary teachers in a sub-urban area in Ogun State, Nigeria. An ethical approval for the conduct of the study was obtained from Babcock University Health Research Ethical Committee.Permission was obtained from both Ogun State Ministry of Education Ikenne and principals of individual schools used.

\section{Participants}

The 143 (75 women and 68 men) participants in this study were all secondary school teachers fromall six secondary schools in this area with a total number of 260 teachers.

\section{Procedure}

A structured questionnaire (see Figure1) was administered by the researcher to the participants after obtaining informed consent from them to collect data for this study. The survey instrument was designed to assess the following:

- Prevalence ofvoice disorders ascertained by affirmation to the question:have you experienced any voice change?'

- Symptoms and its effect on their job

- Work related risk factors

- Health related risk factors

- Behavioral risk factors.

\section{Results}

Of the 143 teachers interviewed, 89gaveaffirmative responses to the question on voice change representing a prevalence of $62.2 \%$. Variable symptoms werereported by the participants with voice disorders. Seventeen described symptoms lasting more than a month.Negative effect of voice disorders to their jobwas reported by 24(27\%) out of 89 respondents with voice disorders.

Table 1. Prevalence of VoiceDisorders by Gender and Age

\begin{tabular}{|l|l|l|l|l|l|}
\hline Voice change & Yes & No & df & $\mathrm{X}^{2}$ & $\mathrm{p}$ \\
\hline Gender & & & 0.2 & 0.6 & 0.2 \\
\hline Male & 45 & 43 & & & \\
\hline Female & 44 & 31 & & & \\
\hline Age & & & 3 & 4.9 & 0.2 \\
\hline $20-29$ & 9 & 9 & & & \\
\hline $30-39$ & 44 & 32 & & & \\
\hline $40-49$ & 28 & 9 & & & \\
\hline $50-59$ & 8 & 4 & & & \\
\hline
\end{tabular}

Chi-square tests conducted indicated no significant relationship between the prevalence of voice disorder and either age or gender(Table1).Potential risk factors for development of voice disorders like health,work related and behavioral variables whentested in this studyshowed theoutcomes in the expected direction. However, there was no statisticalsignificance, as shown in Table 2.

Table 2:Potential risk factors for voice disorders

\begin{tabular}{|l|l|l|l|l|l|}
\hline Potential risk factors $(\mathbf{n}=\mathbf{8 9})$ & Yes & No & df & $\mathbf{X}^{\mathbf{2}}$ & $\mathbf{p}$ \\
\hline Medical conditions & & & 5 & 4 & 0.3 \\
Asthma & 1 & 1 & & & \\
Peptic ulcer & 8 & 1 & & & \\
Diabetes & 0 & 2 & & & \\
Hypertension & 0 & 1 & & & \\
None & 52 & 76 & & & \\
\hline Allergies & 15 & 5 & 4 & 5.0 & 0.3 \\
Cold & 26 & 3 & & & \\
Dust & 6 & 3 & & & \\
Smoke & 0 & 1 & & & \\
Others & 41 & 42 & & & \\
None & 2 & & & & \\
\hline Behavoural variables & 27 & & & \\
Smoking & & & & \\
\hline
\end{tabular}




\begin{tabular}{|c|c|c|c|c|c|}
\hline Alcohol & 3 & 86 & & & \\
\hline Work related variables & & & & & \\
\hline Durationof teaching (Hours) & & & 3 & 1.3 & 0.7 \\
\hline $0-2$ & 16 & 12 & & & \\
\hline $3-4$ & 44 & 29 & & & \\
\hline $5-6$ & 20 & 9 & & & \\
\hline$\geq 7$ & 4 & 9 & & & \\
\hline Job duration & & & & & \\
\hline $0-10$ & 53 & 36 & 3 & 2.7 & 0.4 \\
\hline $11-20$ & 25 & 11 & & & \\
\hline $21-30$ & 10 & 3 & & & \\
\hline 31 and above & & 2 & & & \\
\hline No of classes per day & & & 3 & 2.6 & 0.5 \\
\hline $1-2$ & 4 & 2 & & & \\
\hline $3-4$ & 45 & 28 & & & \\
\hline $5-6$ & 36 & 36 & & & \\
\hline$\geq 7$ & 4 & 0 & & & \\
\hline Number of students/class & & & & & \\
\hline $0-20$ & & & 4 & 5.3 & 0.3 \\
\hline $21-40$ & 19 & 14 & & & \\
\hline $41-60$ & 42 & 26 & & & \\
\hline $61-80$ & 10 & 11 & & & \\
\hline$\geq 81$ & 12 & 2 & & & \\
\hline & 0 & 0 & & & \\
\hline
\end{tabular}

\section{Discussion}

This study revealed a highprevalence of $62.2 \%$ of reported voice disorders among secondary school teachers. This prevalencerate is higher compared to that reported in USA(40\%),Brazil and Spain (20\% to $50 \%)$,Utah and Iowa $(11 \%, 57,7 \%)$ as well asamong the primary school teachers in Lagos,Nigeria $(42 \%)^{3}$.The high prevalence might be related generally to thepoorerworking conditions compared to the communities where the other studies were carried out. The explanation for higher prevalence of voice disorder seen in teachers may be due to the task of teaching itself rather than health and behavioral variables. These work related risk factors, which showed the expected direction in this study, were not statistically significant.Variables suggested in previous studies(Roy et al.,2004) including medical conditions such as Peptic Ulcer Disease ,respiratory allergy,alcohol ingestion, smoking and work related variables showed no significant relationship with voice disorders in this study.These findingswerealso corroborated by Kristen PHiggins (2012). However, it is alsopossible that the findings occurred by chance and may not be a reflection of negative correlation between the above variables and voice disorder.

Although, common symptoms such ashoarseness, vocal discomfort, decreased loudness and pitch changes were reportedin this study as in other studies (Jonsdottir et al., (2002), Roy et al.,(2004),Verdolini et al., ( 2001), the most common symptomwas low voice (39\%).For instance, Jonsdottir et al., (2002), Roy et al.,(2004),Verdolini et al., ( 2001) ${ }^{12}$ reported about $15 \%$ with thesesymptoms most of the time.The analysis of demographic variables in this study revealed no statistically significant difference inprevalence of voice disorders between the male and female teachers.This is different from past studies which suggested that women may be at higher risk then men(Grillo et al., 2011,Jonssdottir et al .,2002,Rantala., et al., 2002).However in this study,voice disorders were marginally higher in men,even with women being the higher respondents. However, therewasno gender effect on the development of voice disorders,as reported by Kristen P.Higgins, 2012, with similar findings. Nonetheless, more research with larger sample size willbe required to establish this finding.

The risk ofvoice disorders, had been associated with increasing age in prior studies with a greater prevalence among individuals between ages40and $50^{17}$. This is not supported by our findings inthis study asmost of the teachers with voice disorders $(76 \%)$, were between the ages of 30-39(n=44). Although the trend was in the expected direction, possible associated risk factors for the development of voice disorders examined in this study showed no statistically significant relationship to voice disorders.

\section{Conclusion}

The results from this study suggest that the task of teaching has significant demanding effects on the voice and the higher prevalence rate of voice disorders in over half ofthe secondary school teachers in this study is of great concern. Demographic and behavioral factors commonly reportedas increasing voice disorders apparentlyhad little effects on the prevalence of voice disorder in this study. Future studies with bigger sample sizes atdifferent levels of education across geographical locations as well as fibreoptic laryngoscopy of teachersare necessary for a better understanding of the unique pathophysiology of voice disorders in this community. 


\section{References}

[1]. Kosztyla-Hojna,B.,Rogowski,m.,Ruczaj,j.,Pepinski,w.\&Lobaczuk-sitnink,A.(2004).An analysis of occupational dysphonia diagnosed in the north -east of Poland. International Journal of occupational Medicine and Environmental Health, 17(2), 273-278.

[2]. Sataloff RT. Professional voice users: The evaluation of voice disorders occup med 2001., 16(4)633-47.

[3]. Roy,N.,Merrill,R.N.,Thibcault,S.,Parsa,R.A.,Gray,S.D.,\&Smith,E.M(2004).Prevalence of voice disorders in teachers and general population. Journal of Speech, Language and Hearing Research, 47,281-293.

[4]. Akinbode,R ,Lamk, B,Ayres,J.G .,Sadhra,S.,Journal of occupational medicine(London).2014 Jul.,64(5):382-6.

[5]. Sala,E.,Laine,A.,Simberg,S.,Vehmas(2005). The prevalence of voice disorders among day care teachers compared to nurses.A questionnaire and clinical study.Journal of voice 15(3),413-423.

[6]. McCabe ,D.s\&Titze,I.R(2002).Chart and therapy for treating fatique among public school teachers :A preliminary study.American journal of speech,language pathology,11,356-369.

[7]. Roy,N.,Weinrich,B.,Gray,S.D.,Tanner,K.,Stample .J.C.,\&Spienzci,C.M.(2003).Three treatment for teachers with voice disorders. A randomized clinical trial. Journal of speech ,Language and Hearing Research ,46,670-688.

[8]. Higgins,Kristen,P.,(2006).The prevalence of voice disorders In University Teaching Faculty .Electronic theses and dissertation. Paper 286 .

[9]. Verdolin,k.,\&Ramig L.o(2001).Review: Occupational risk for voice problems,Logopedicsphoniatricsvocology,26,37-46

[10]. Arikoski,M.,Tommila.,\&Laukkaneri,A.(2002).Changes in voice during a day in normal voices without vocal loading Logepedicsphoniatricsvocology,27,118-128.

[11]. Roy,N.,Merrill,R.M.,Thibealt ,S.,Gray,S.D.,\&Smith ,E.M.(2004).Voice disorders in teachers and general population.Effects on work performance ,attendance and future career choices.Journal of Speech.,Language and Hearing Research,47,542-51.

[12]. welham,N.V.,\&Maclagan,M.A.(2003).vocal fatique:current knowledge .Journal of voice disorders 17,21-30.

[13]. Sandage ,M.J.,\&Emerich ,k.(2003).Singing voice :special considerations for evaluation.ASHA leader,13.

[14]. Vikman,E.voice problems at work; a challenge for occupational safety and health arrangement .Folia phonicit et logop.,52,120-125.

[15]. Delcor, N.S.,Araujo ,T.M.,Reis ,Parto,L.A.,Carvaho FM. Cad s audepublica 2004:20(1),187-196.

[16]. Sliwinska-kowalska M,Niebudeka -Roqusz,FiszerM,Cos-Spychalska.The prevalence and risk factors for occupational voice disorders in teachers.Folia phoniatrilogop.2006;58(2).85-101.

[17]. Methiesori,L.The voice and its disorders, $6^{\text {th }}$ Edition.London,Philadelphia publishers 2001

[18]. Sebastal, M.Impact and prevation of voice disorders in the teaching profession:Embracing the consumers view.Journal of voice disorders 2002,215-228

[19]. American Speech Language Hearing Association (2005).Accoustic in educational settings:position statement

[20]. Lanre,Olaitani,Oyerinde,Obiyemi\&Kayode.Prevalence of job stress among primary school teachers in South West Nigeria African Journal of Microbiology Research.March 2010.vol 4 (5).pp 333-342.

[21]. Simberg ,S.,Sala,E.,Vehamas,K.,\&Laine,A.(2005).Changes in the prevalence of vocal sysmptoms among teachers during a twelve year period. Journal of voice, 19,95-102.

[22]. Anderson,Titze,I.R.,Svec,J.G.,\&Popolo,P.S.(2003).Vocal dose measure .Quantifying accumulated vibration exposure in vocal fold tissues. Journal of Speech ,Language and Hearing Research,46,670-688.

[23]. Martins,Laukkanen,A.M.,Llomaki ,I.Leppanen,K.S.,\&Vilkman,E(2008).Acoustic measures and self report of vocal fatigue by female teachers. Journal of voice, 22,283-289.

[24]. Smith,E.,Gray,S.D.,Dove,H.,Kirchner.,\&Heras,H.(1997).Frequency and effects of teachers voice problems. Journal of voice, 11,8187.

[25]. Houltel, Morrow,S.L., \&Connor ,N.P(2011).Comparison of voice profile between elementary classroom and music teachers Journal of voice, $25,367-372$.

[26]. Grillo,E.U.\&Fugowski,J(2011).Voice characteristics of female physical education student teachers..Journal of voice 25 ,149-157.

[27]. Margaret,O.A,(2004).Research Methodology with Statistics For Health and Social Sciences. 